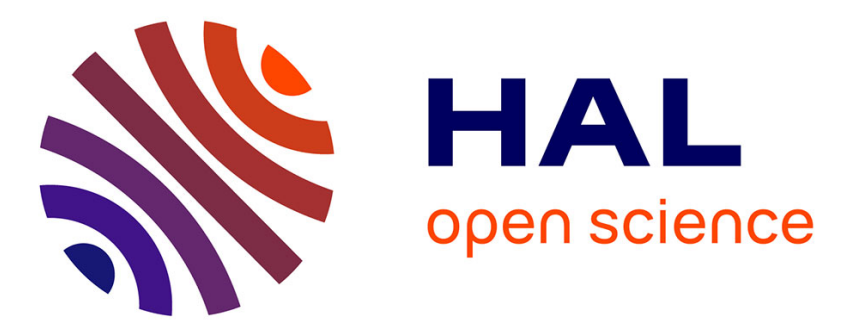

\title{
An experimental investigation of the influence of the moving people on the indoor radio propagation
}

\author{
Gheorghe Zaharia, Ghaïs El Zein, Jacques Citerne
}

\section{To cite this version:}

Gheorghe Zaharia, Ghaïs El Zein, Jacques Citerne. An experimental investigation of the influence of the moving people on the indoor radio propagation. IEEE-APS International Symposium, Seattle, 1994, Jun 1994, Seattle, United States. pp.1898-1901, 10.1109/APS.1994.408167 . hal-00875631

\section{HAL Id: hal-00875631 \\ https://hal.science/hal-00875631}

Submitted on 5 Nov 2013

HAL is a multi-disciplinary open access archive for the deposit and dissemination of scientific research documents, whether they are published or not. The documents may come from teaching and research institutions in France or abroad, or from public or private research centers.
L'archive ouverte pluridisciplinaire HAL, est destinée au dépôt et à la diffusion de documents scientifiques de niveau recherche, publiés ou non, émanant des établissements d'enseignement et de recherche français ou étrangers, des laboratoires publics ou privés. 


\title{
AN EXPERIMENTAL INVESTLGATION OF THE INFLUENCE OF THE MOVING PEOPLE ON THE INDOOR RADIO PROPACATION
}

\author{
Gh. Zaharia*, G. El Zein and J. Citertie \\ Laboratoire Composants \& Systemes pour Télfcommunications \\ URA CNRS 834, DSA, 35043 Rennes Cédex, France \\ phone: (33) - 99.28.65.07, fax: $(33)-99.38 .62 .48$.
}

\section{ABSTRACT}

Using a new scenario for measurements, the influence of the hutran traffic on the indoor radio propagation is investigated. This new scenario permits to obtain a signature of moving people all day long. In order to obtain better results for the radio coverage, a new random term must complete the results obtained for power-distance relationship in the absence of moving people.

\section{INTRODUCTION}

The indoor radio propagation has been an active area of research in recent years, dae to the use of radio for indoor data and voice communications within office buildings, convention centers, hospitals, factories and apartment buildings. There have been several studies of the power losses, statistics of the RMS defay spread, polarisation diversity and attempts to model the indtor radjo channel. The effects of time variations of the characteristics of the indoor tadio propagation caused by human traffic between the transmitter and the recejer bave not been thoroughly inwestigaled. Some results are presented in [1-3].

Frevious results of the indoor radio propagation [4-5] have been obtained from measurements performed during the night or the week end, in order to avoid the effects of the presence of people. The surrounding environment was kept stationary by preventing movements during the data acquisition. This perrits to investigate the influence of the basic building structure (watls, floors and ceillings) and the furniture. The time invariance of the indoor radio channel permits to obtain reproductible and verifiable results.

However, buildings represent a complex environment. Besides the basic building structure, fumishings and people serve as scatterers of radio waves. The presence of the moving people detemines variations of the power of the received signal and distutbances of the rnultipath propagation.

A characterstic of the results presented in this paper is the manner to obtain the movements of the people. For example, in [1] two scenarios are described:

a) two persons walk briskly around the transmitter and the receiver;

b) one antenua is ratated by a person around a given location.

In this paper, both antennas are placed in a research laboratory, while the movements represent the nabural activity of the researchers. students, visitors, technical and administrative staff during the whole day ( 24 hours). This allows us to obtain realistic results, reflecting a normal behavior of the moving people.

\section{DESCRIPTION OF THE MEASUREMENTS}

The messurement system [4] is built up around a $\mathrm{HP}$ B753C network andyzer which generates a swept frequency signal $(+20 \mathrm{dBm})$, from $800 \mathrm{MHz}$ to I $\mathrm{GHz}$ in 801 equally spaced steps and analyses the received signal. The outpul of the network analyzer is connected to the transmitting (Tx) antenna through a $50 \mathrm{~m}$ coaxial cable with $8 \mathrm{~dB}$ attenuation. The calibration is performed at the output of this cable. The signal from the receiving ( $R x$ ) antenna is teturned through i $4.5 \mathrm{~m}$ coaxial cable to the network analyzer to determine the $S_{21}$ parameter. During the measurements, both antennas were kept fixed and placed at the same height: $1.5 \mathrm{~m}$. For each localion of the Rx antenna, the magnitude of 
$S_{21}$ in $\mathrm{dB}$ (representing the power loss) and the impulse response of the chanme! (computed via an Inverse Fourier Transform) were recorded for futher analysis.

The measurements start at midnight and last 24 hours. Each minute a measurement is perfomed: one minute for the power loss (on the first channel of the network aralyzer) and one minute for the impulise response (on the second channel). The daka is sended via an IEEE-488 bus io a Teltronix 4041 computer / controller and stored on the bard disk (a 4041 Disk Drive Uait).

The measurements are performed at the ground floor of the LCST labotatory. Tha $\mathrm{Rx}$ antenna is placed in the central room, whereas the Tx antenna is located at one extremity of the laboratory. Therefore, the sceess to the others rooms imposes the passing near the $\mathrm{Rx}$ antenra. The stairs to the first floor are placed between the antennas. Each person going upstairs or downstairs catuses a disturbance of the multiputh propagation and a small shadowing of the LOS.

\section{DATA ANALYSIS}

The main objective of these measurements is to deternine the modifications of the indoor radio propagation charactetistics cauged by human traffic. Consequently, the estimation of the radjo coverage obtained in [5] in the absence of the moving people can be corrected, in order to obtain realistic results, reflecting a nomal behavior of the moving people.

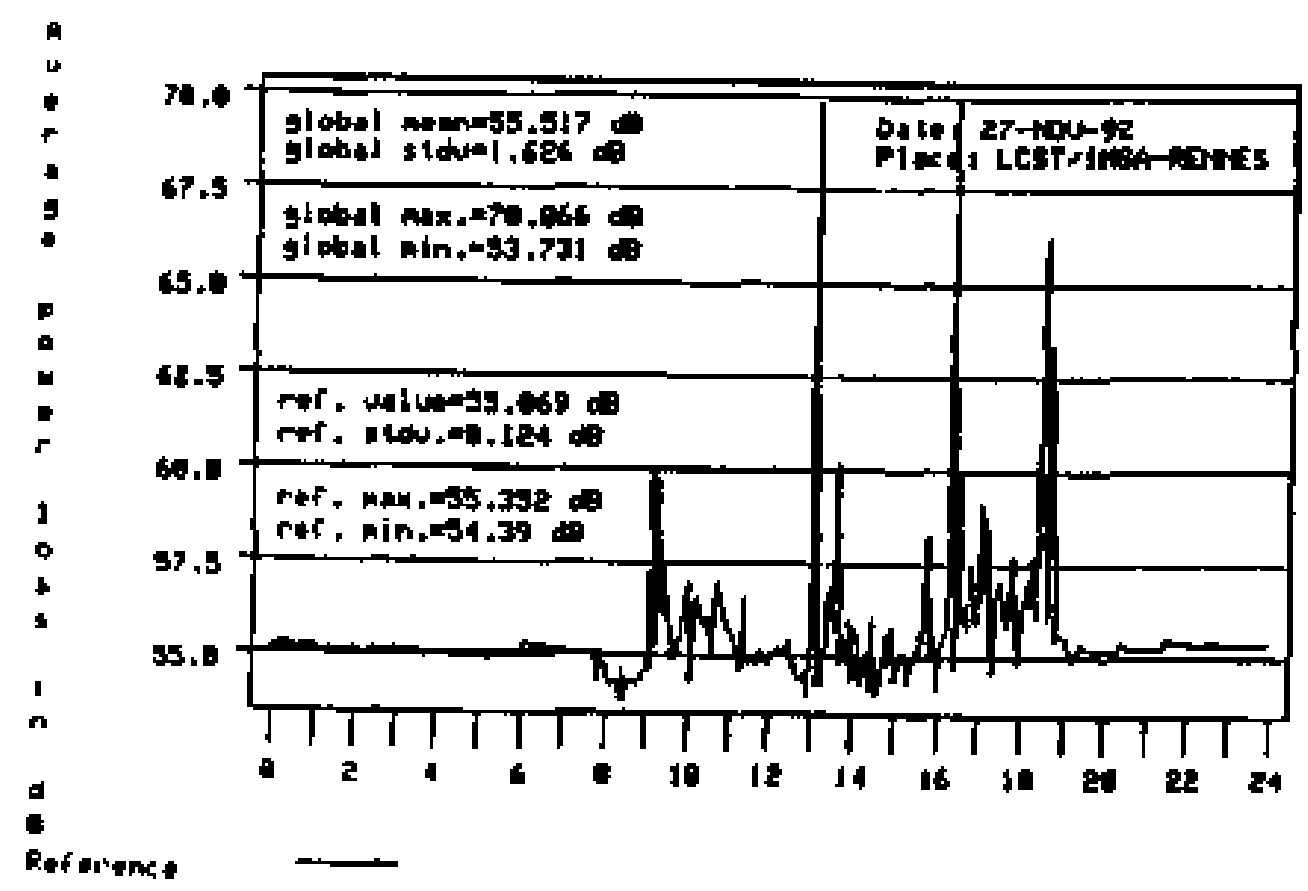

Jim in mant

Fig.1. Temporal power loss measurements

Fig. 1. shows a first result obtained for the average power loss. During the night $(0-8 \mathrm{~h})$, the bulding was deserted. Therefore, the chandel can be considered stationary. The power loss is practically constant (5S dB), with a small standard deviation $(0.124 \mathrm{~dB})$. This value repregents the reference.

During the day, duc to the human traffic, the power loss has jmportant variations, from $53.7 \mathrm{~dB}$ up to $70 \mathrm{~dB}$. The most values are greater than the reference, so the shadowing is preporderant. However, the smaller values indicate a weak distubance of the multipath propagation. The greatest values are obtained about $8 \mathrm{~h}$ (the arrival or the researchers and the administrative stafD). 13 $h$ (Junch time) and 18 h 30 min (the departure of the majority of the researchers). Smaller vatiations are obtained about $9 \mathrm{~h} 30$ min $-10 \mathrm{~h}$ and $16 \mathrm{~h}-16 \mathrm{~h} 30 \mathrm{~min}$ (coltee breaks). Alter 20 h the power loss rebecomes practically constant.

Sirmilar results can be oblained for the RMS delay spread, compuled from 
the impulse response of the channel (tig.2). During the night, the delay spread is practicalty constant: $21.8 \mathrm{~ns}$, with a small slandard deviation (0.38 ns). During the day, one can note variatjons between 12.3 ns and 33.23 ns.

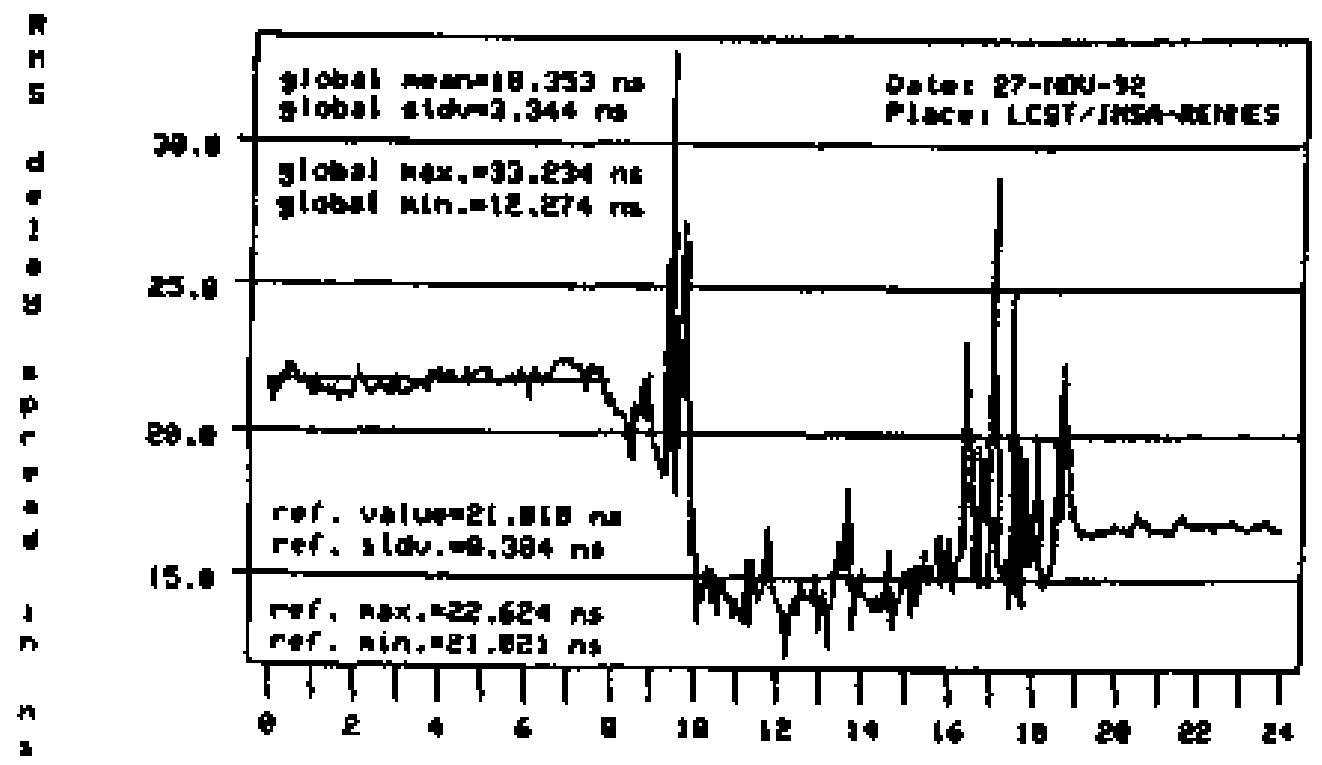

Aoterone

Tim in hourt

\section{Flg.2. Temporal RMS delay spread measuremenis}

This time, there is a difference between the reference value $(0-8 \mathrm{~h})$ and the final (practically) constant value, about 17 ns. This can be explained by the modifications during the day of the position of several carts made of metal and equipped with pneuratic tires, used for various measurement apparatus. As a general remark for these figures, one can note the strong correlation between the human activity and the obtained fesults.

For an experimental investigation of the stationarity of the indoor radio channel in the absence of the bumgn traffic, the above results are nat sufficient. It is possible to obtain the sume average power loss for different frequency responses of the same RMS delay spread for different impulse responses of the indoor radio channel. Therefore, it was necessary to consider the euclidean distance between a refertence frequency/mpulse response and each response recorded during the day. Practicaly, the refertoce response was computed as the average of the first 120 responges recorded during the night ( 0 - 8h);

$$
I=[\pi(1), r(2), \ldots, r(n)]=\frac{1}{120} \sum_{k=1}^{120}\left[x_{k}(1), x_{k}(2)_{,+\ldots,} x_{k}(n)\right]
$$

Using this reference response, the normalized euclidean distance between a response $x_{k}=\left[x_{k}(1), x_{k}(2), \ldots, x_{k}(n)\right]$ can be computed as:

$$
d\left(x_{k}, r\right)=\sqrt{\frac{1}{n} \sum_{i=1}^{\pi}\left[x_{k}(i)-r(i)\right]^{2}}, \quad k=\overline{1,720}
$$

Fig.3. shows a plot of the nomatized euclidean distance $d\left(x_{k}, r\right)$ for the power loss. One can remark the sirailarity between this result and the other one shown in Fig.1. Practically, this new paraneter can be used as well as the average power loss for the analysis of the influence of the human traffic on the indoor radio channel. Using this new result we can prove the stationarity of this channel in the absence of the movitg people. A simular approach was considered for the impulse response of the channel. Using the above results it is possible to obtain a cumulative distribution for the power loss and the RMS delay spread and 


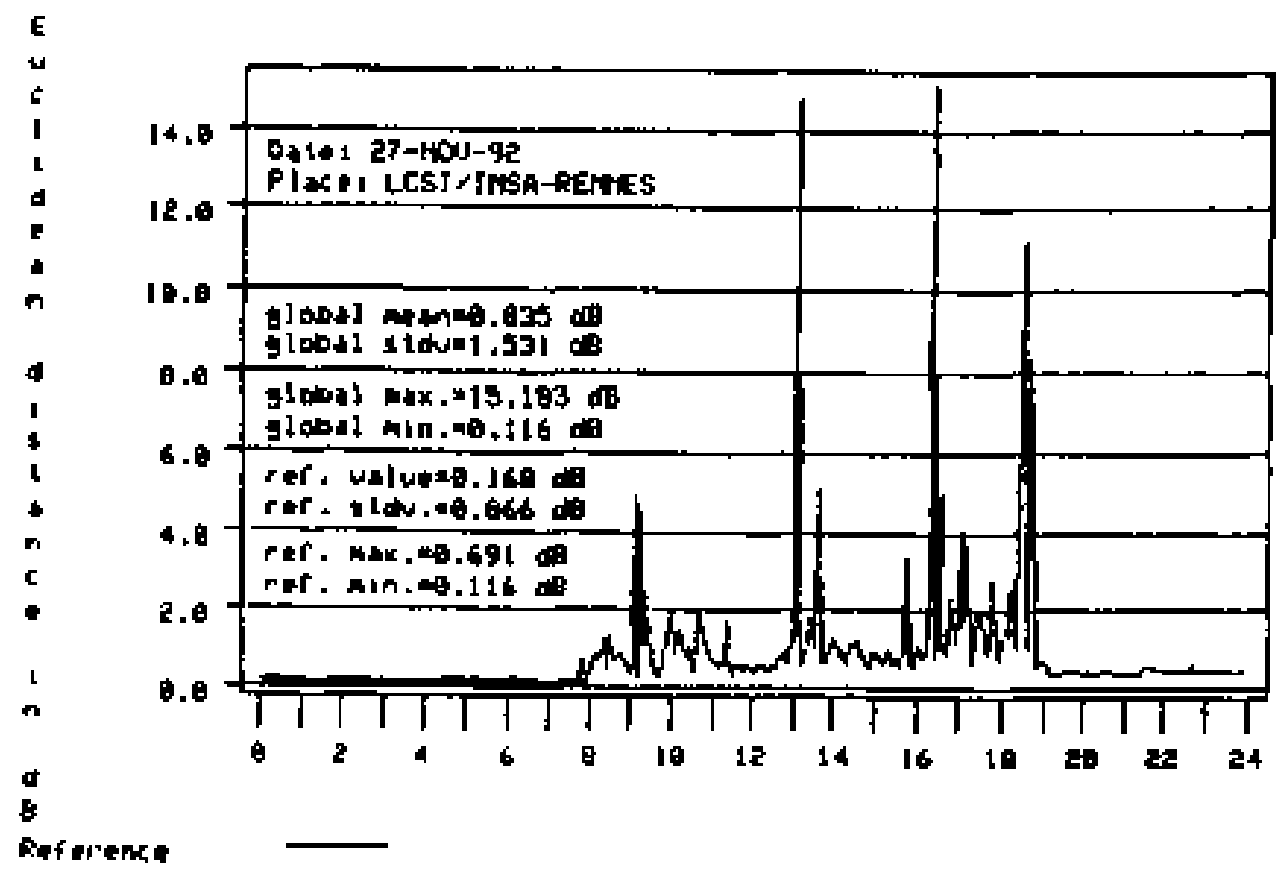

Tine in hedr:

Ftg.3. Normalized euclidean distance of the power loss curves versus lime

to compare it with a classical distribution as Rician [2-31, Rayleigh [1,3], lognormal and Weibull [1]. Duc to the described scenario of these measurements, the obtained results charactetize the influence of a natural human traffic on the indoor propagation characteristics.

\section{CONCLUSION}

A new scenario for the analysis of the influence of the moving people to the power loss and RMS delay spread has been described in this paper. Using the data obtained fromt the measurements it is possible to deduce in a simple marner a signature of the human trafire all day long. From the variations of the power Joss values it is possible to obtaine an improved model for the power - distance relationship with a deterministic term in da which describes the long scate variations of the power loss versus distance, a deterministic term which characterizes the small scale variations with the distance of the power Joss, a random term which completes the model in the absence of people and a new random tem characterizing the influe net of the human traffic on the power Joss. Using this improved model, it is possibte to obtain more realistic estimations of the radio coverage in the buildings.

\section{REFERENCES}

[1] Ganesh, R. and PahJuvan, K.: "Effects of traffic and local mowements on multipath characterislics of an indoor radio channel", Electron.Letl., Vol.26. No. 12, 1990, Pp. 810-812

[2] Rappaport, T.S. and McGillern, C.D.: "UHF fading in faclories", IEEE J. Sel. Areas Commun., wol SAC-7, No. 1 , jan. 1989

[3] Mizuno, M, and Bergljung, C: "Characterizalion of indoor propagation using amplitude distributions', Proc. of ISAP '89, aug. 1989, Vol.3, pp.793796

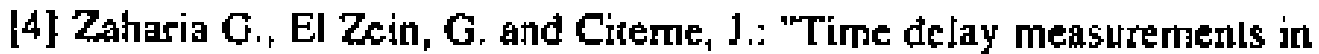
the frequency domain for indoor propagation". IEEE AP-S Dig." Chicago IL., 1992, pp.1384-139!

[5] Zaharia, G., El Zein, G. and Citerne, J.: "Analysis of the indoof propegation losses For the portable phone Pointel", IEEE AF-S Dig., Ann Arbor. MI.. [993. pp. 1069.]972 